\title{
Early mortality from colorectal cancer in England: a retrospective observational study of the factors associated with death in the first year after diagnosis
}

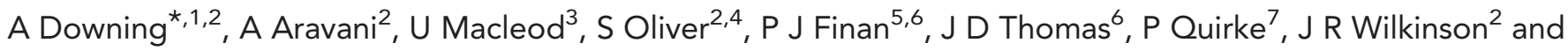
E J A Morris ${ }^{1,2}$

${ }^{1}$ Cancer Epidemiology Group, Centre for Epidemiology and Biostatistics, University of Leeds, Level 6, Bexley Wing, St James's Institute of Oncology, St James's University Hospital, Leeds LS9 7TF, UK; ${ }^{2}$ Northern and Yorkshire Cancer Registry and Information Service, Level 6, Bexley Wing, St James's Institute of Oncology, St James's Hospital Leeds, Leeds LS9 7TF, UK; ${ }^{3}$ Hull York Medical School, University of Hull, Hull HU6 7RX, UK; ${ }^{4}$ Department of Health Sciences, University of York and the Hull York Medical School, Seebohm Rowntree Building, Heslington, York YO10 5DD, UK; ${ }^{5}$ John Goligher Colorectal Unit, St James's University Hospital, Leeds LS9 7TF, UK; ${ }^{6}$ National Cancer Intelligence Network, 18th Floor Portland House, Bressenden Place, London SW1E 5RS, UK and ${ }^{7}$ Pathology and Tumour Biology, Leeds Institute of Molecular Medicine, Level 4 Wellcome Trust Brenner Building, St James's University Hospital, Leeds LS9 7TF, UK
\end{abstract}

Background: The United Kingdom performs poorly in international comparisons of colorectal cancer survival with much of the deficit owing to high numbers of deaths close to the time of diagnosis. This retrospective cohort study investigates the patient, tumour and treatment characteristics of those who die in the first year after diagnosis of their disease.

Methods: Patients diagnosed with colon $(n=65733)$ or rectal $(n=26123)$ cancer in England between 2006 and 2008 were identified in the National Cancer Data Repository. Multivariable logistic regression was used to investigate the odds of death within 1 month, 1-3 months and 3-12 months after diagnosis.

Results: In all, $11.5 \%$ of colon and $5.4 \%$ of rectal cancer patients died within a month of diagnosis: this proportion decreased significantly over the study period. For both cancer sites, older age, stage at diagnosis, deprivation and emergency presentation were associated with early death. Individuals who died shortly after diagnosis were also more likely to have missing data about important prognostic factors such as disease stage and treatment.

Conclusion: Using routinely collected data, at no inconvenience to patients, we have identified some important areas relating to early deaths from colorectal cancer, which merit further research.

Five-year survival rates from colon and rectal cancer vary significantly across Europe (Verdecchia et al, 2007), with outcomes in the United Kingdom falling short of those seen in many comparable European countries, such as Norway and Sweden.
Recent studies have demonstrated that this survival deficit is primarily due to a relatively high number of excess deaths occurring (mainly in older patients) in the first few months after diagnosis (Engholm et al, 2007; Folkesson et al, 2009; Moller et al, 
2010; Morris et al, 2011). What has not been clear is why such a high proportion of individuals in the United Kingdom die so rapidly after diagnosis. Advanced stage of disease at presentation, high levels of co-morbidity preventing active treatment, poor quality of care and differences in access to gold-standard treatments have all been suggested as potential explanations. However, until recently, the paucity of population-level data suitable to explore these factors has prevented an assessment of their relative contribution to rapidly fatal disease. The establishment by the National Cancer Intelligence Network (NCIN) of the National Cancer Data Repository (NCDR) has done much to address this (National Cancer Intelligence Network, 2011). This study makes use of the NCDR to quantify at a population level the patient, tumour and treatment characteristics of individuals with colon and rectal cancer in England who died within 1 year of diagnosis, in order to establish a clearer understanding of the factors associated with early mortality.

\section{METHODS}

Information was extracted from the NCDR on all patients diagnosed with a first primary colon (International Classification of Diseases Version 10 (ICD10) (World Health Organisation, 2004) code C18-19) or rectal (ICD10 code C20) cancer in England between 2006 and 2008. Patient and tumour information was obtained from the cancer registry component of the NCDR. Postcode of residence at diagnosis was used to measure socioeconomic background using the income domain of the 2004 Index of Multiple Deprivation (Office of the Deputy Prime Minister, 2005).

A number of variables were derived using the linked data available in the NCDR. A Charlson co-morbidity score (Charlson et al, 1987) was calculated for each individual linked to Hospital Episodes Statistics (HES) based on the diagnostic reasons for any hospital admissions in the year preceding diagnosis of their colorectal tumour. Patients were grouped into Charlson score categories of $0,1,2$ or $\geqslant 3$ and unknown (if the patient could not be identified in HES). A primary procedure (as defined by the OPCS Classification of Interventions and Procedures version 4 (NHS Connecting for Health, 2009) was sought for every individual identified in HES. A hierarchy of primary procedures occurring within 12 months of diagnosis was established: major resection; minor resection; palliative procedures. Individuals were allocated to the highest category compatible with their HES records. If no primary procedure could be identified, individuals were allocated to the 'no surgical treatment' category. Individuals that could not be identified in HES were included in a separate 'unknown' category. The method of presentation at hospital was categorised as: elective; emergency or unknown by combining the admission method from the relevant HES episodes with the 'route to diagnosis' information from the NCDR (Elliss-Brookes et al, 2012). The 'route to diagnosis' uses multiple data sources to characterise a 'pathway' to diagnosis, one of which is emergency presentation.

Cases were split into groups by survival time after diagnosis: $\leqslant 1$ month (0-30 days), 1-3 months (31-90 days), 3-12 months (91-365 days), alive at 1 year (>365 days). Logistic regression was used to investigate the odds of death within 1 month, 1-3 months and 3-12 months after adjustment for patient, tumour and treatment characteristics. Colon and rectal cancers were analysed separately (see Supplementary Tables online for study population characteristics). The colon cancer model was built with a multi-level structure (with patients nested within cancer registries) as cancer registry was a significant factor in the single-level model.

\section{RESULTS}

During the study period 65733 and 26123 individuals were diagnosed with colon or rectal cancer, respectively. Of those diagnosed with colon cancer, $33.4 \%$ died within a year: $11.5 \%$ within 1 month, $8.2 \%$ within $1-3$ months and $13.7 \%$ within $3-12$ months. For rectal cancer, the proportion dying within 12 months of diagnosis was lower (24.8\%): 5.4\% died within a month of diagnosis, $5.9 \%$ within $1-3$ months and $13.5 \%$ within $3-12$ months (Figure 1).

For both the colon and rectal cancer populations, patients dying within 1 month of diagnosis were more likely to be older, female, have received no surgical treatment, have higher co-morbidity scores, have more advanced disease and present as an emergency (see Supplementary Tables online for the study population characteristics). In addition, the proportion of cases missing information on stage at diagnosis, co-morbidity, surgical treatment or method of presentation was greater in those who died close to the time of diagnosis.

The multivariable analysis for individuals with colon cancer demonstrated a significant reduction in the odds of dying within 1 month of diagnosis in successive diagnosis years (OR 0.91, 95\% CI: $0.88-0.94$ ) but no change in the odds of dying between 1-3 and 312 months from diagnosis. (Table 1) There was a positive association between age and the odds of death within each survival period. The odds of dying within 1 month of diagnosis were higher amongst individuals who received palliative surgery (OR 1.26, 95\% CI: $1.10-1.45$ ) or no surgical treatment (OR 2.68, 95\% CI: $2.47-$ 2.91) compared with a surgical resection, but were greatest for the unknown treatment category (OR 11.20, 95\% CI: 10.07-12.46). In the latter survival periods, the odds of death for this unknown category reduced (but remained significant), whereas the odds increased for both the palliative surgery and no surgery categories. Increasing co-morbidity, deprivation and Dukes' stage were associated with increased odds of death in all three survival periods. Individuals with no staging information had increased odds of death in each period but this was greatest in the first month after diagnosis (OR 8.11, 95\% CI: 6.38-10.30 compared with Dukes A). Finally, those presenting as an emergency had significantly increased odds of early death.

The multivariable rectal cancer model results were very similar to those for colon cancer (Table 2). The main differences were a reduction in the odds of death over the study period within both 1 month and 1-3 months of diagnosis (OR 0.87, 95\% CI: 0.81-0.95 and OR 0.91, 95\% CI: 0.85-0.97, respectively per year increase) and

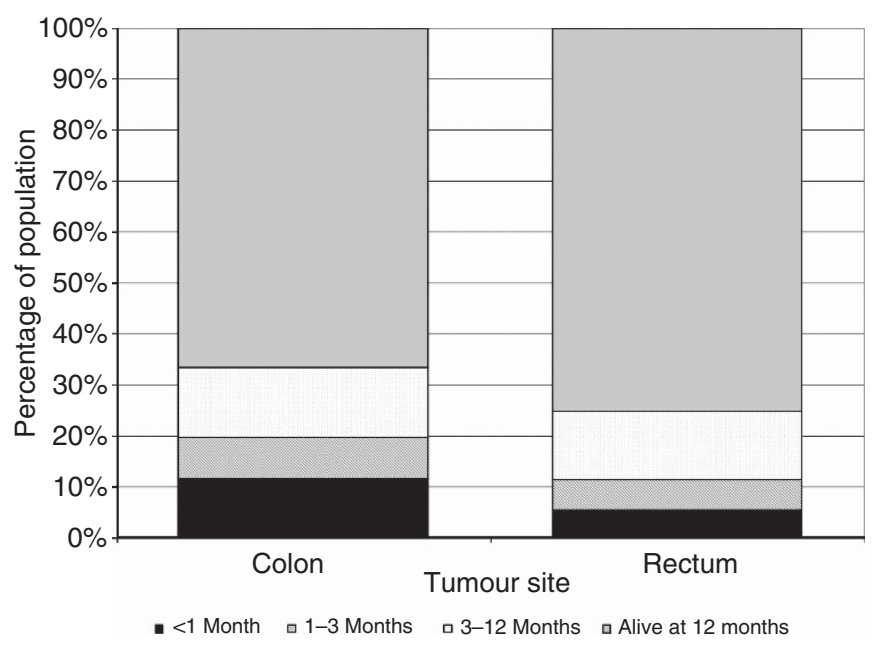

Figure 1. Proportion of the colon and rectal cancer populations in relation to the time from diagnosis until death. 
Table 1. Multivariable analysis of individuals with colon cancer in relation to time from diagnosis

\section{Odds of death ${ }^{a}$ within}

\begin{tabular}{|c|c|c|c|c|c|c|}
\hline \multirow[b]{2}{*}{ Characteristic } & \multicolumn{2}{|c|}{1 Month of diagnosis } & \multicolumn{2}{|c|}{ 1-3 Months of diagnosis } & \multicolumn{2}{|c|}{ 3-12 Months of diagnosis } \\
\hline & OR & $95 \% \mathrm{Cl}$ & OR & $95 \% \mathrm{Cl}$ & OR & $95 \% \mathrm{Cl}$ \\
\hline Year of diagnosis & 0.91 & $0.88-0.94$ & 0.97 & $0.94-1.01$ & 0.98 & $0.95-1.01$ \\
\hline Age at diagnosis & 1.05 & $1.04-1.05$ & 1.03 & $1.03-1.04$ & 1.03 & $1.03-1.04$ \\
\hline \multicolumn{7}{|l|}{ Sex } \\
\hline $\begin{array}{l}\text { Male } \\
\text { Female }\end{array}$ & $\begin{array}{l}1.00 \\
0.97\end{array}$ & $0.91-1.03$ & $\begin{array}{l}1.00 \\
0.97\end{array}$ & $0.91-1.03$ & $\begin{array}{l}1.00 \\
1.09\end{array}$ & $1.03-1.15$ \\
\hline
\end{tabular}

\section{Surgical treatment}

\begin{tabular}{|c|c|c|c|c|c|c|}
\hline Resection & 1.00 & & 1.00 & & 1.00 & \\
\hline Palliative & 1.26 & $1.10-1.45$ & 2.51 & $2.22-2.84$ & 5.19 & $4.65-5.80$ \\
\hline No surgery & 2.68 & $2.47-2.91$ & 3.68 & $3.39-4.00$ & 3.62 & $3.33-3.88$ \\
\hline Unknown & 11.20 & $10.07-12.46$ & 3.05 & $2.62-3.55$ & 1.84 & $1.58-2.14$ \\
\hline
\end{tabular}

Charlson co-morbidity score

\begin{tabular}{|c|c|c|c|c|c|c|}
\hline 0 & 1.00 & & 1.00 & & 1.00 & \\
\hline 1 & 1.48 & $1.37-1.60$ & 1.08 & 0.99-1.18 & 1.30 & $1.21-1.41$ \\
\hline 2 & 1.69 & $1.51-1.89$ & 1.42 & $1.26-1.62$ & 1.41 & $1.26-1.59$ \\
\hline$\geqslant 3$ & 1.97 & $1.75-2.22$ & 1.39 & $1.20-1.61$ & 1.96 & $1.70-2.26$ \\
\hline Unknown ${ }^{\mathrm{b}}$ & Omitted & & Omitted & & Omitted & \\
\hline
\end{tabular}

\section{Index of Multiple Deprivation income category}

\begin{tabular}{|c|c|c|c|c|c|c|}
\hline Most affluent & 1.00 & & 1.00 & & 1.00 & \\
\hline 2 & 1.10 & $1.01-1.21$ & 1.11 & $1.00-1.22$ & 1.09 & $1.01-1.19$ \\
\hline 3 & 1.13 & $1.03-1.24$ & 1.15 & $1.04-1.27$ & 1.14 & $1.05-1.24$ \\
\hline 4 & 1.26 & $1.15-1.38$ & 1.23 & $1.12-1.36$ & 1.18 & $1.08-1.29$ \\
\hline Most deprived & 1.30 & $1.18-1.43$ & 1.28 & $1.16-1.43$ & 1.24 & $1.14-1.36$ \\
\hline Unknown ${ }^{b}$ & 1.65 & $1.31-2.08$ & 1.13 & $0.86-1.48$ & 1.18 & $0.95-1.47$ \\
\hline
\end{tabular}

Dukes' stage at diagnosis

\begin{tabular}{|c|c|c|c|c|c|c|}
\hline A & 1.00 & & 1.00 & & 1.00 & \\
\hline B & 2.53 & $1.98-3.23$ & 1.06 & $0.87-1.29$ & 1.46 & $1.23-1.74$ \\
\hline C & 3.18 & $2.49-4.05$ & 1.51 & $1.24-1.83$ & 3.92 & $3.33-4.62$ \\
\hline D & 5.59 & $4.39-7.12$ & 5.17 & $4.29-6.25$ & 14.63 & $12.39-17.28$ \\
\hline Unknown & 8.11 & $6.38-10.30$ & 3.23 & $2.67-3.91$ & 6.27 & $5.29-7.42$ \\
\hline
\end{tabular}

Method of presentation

\begin{tabular}{|l|l|l|l|r|r|r|}
\hline Elective & 1.00 & & 1.00 & 1.00 & $1.90-2.16$ & 1.79 \\
Emergency & 4.24 & $3.98-4.51$ & 2.03 & $0.69-1.89$ & $0.75-1.22$ & $0.97-1.23$ \\
\hline
\end{tabular}

Abbreviations: $\mathrm{Cl}=$ confidence interval; $\mathrm{OR}=$ odds ratio.

${ }^{a}$ Mutually adjusted for all characteristics listed.

${ }^{b}$ Omitted owing to collinearity with unknown surgical treatment.

a 21-fold increase in the odds of dying within 1 month of diagnosis in the unknown treatment category (OR 21.59, 95\% CI: 17.0327.36 compared with having a resection).

\section{DISCUSSION}

This retrospective study found that individuals with both colon and rectal tumours who died soon after their diagnosis were likely to be elderly, live in more deprived areas, present as emergencies, have advanced disease at diagnosis and fail to receive any radical treatment. This is in line with evidence from several other published studies from European populations (Engholm et al, 2007; Folkesson et al, 2009; Brewster et al, 2011; Morris et al, 2011;
Moller et al, 2012). The results also indicate that the odds of a very early death (within a month of diagnosis) decreased over the study period.

A new observation was the high proportion of missing data amongst those who die very rapidly after diagnosis, especially for stage of disease and treatment type. The reasons for this are complex but might include no or limited contact with secondary care owing to rapidly fatal disease, insufficient pathological and/or radiological information for staging, failure to record information in the patients' notes and treatment in private hospitals (not included in HES). Alternatively, the NCDR may be missing relevant inpatient episodes for individuals whose cancer diagnosis has been miscoded. Linkage between cancer registration data and inpatient HES records within the NCDR is currently only available for individuals for whom at least one episode of care contains a 
Table 2. Multivariable analysis of individuals with rectal cancer in relation to time from diagnosis

Odds of death ${ }^{\mathrm{a}}$ within

\begin{tabular}{|c|c|c|c|c|c|c|}
\hline \multirow[b]{2}{*}{ Characteristic } & \multicolumn{2}{|c|}{1 Month of diagnosis } & \multicolumn{2}{|c|}{ 1-3 Months of diagnosis } & \multicolumn{2}{|c|}{ 3-12 Months of diagnosis } \\
\hline & OR & $95 \% \mathrm{Cl}$ & OR & $95 \% \mathrm{Cl}$ & OR & $95 \% \mathrm{Cl}$ \\
\hline Year of diagnosis & 0.87 & $0.81-0.95$ & 0.91 & $0.85-0.97$ & 0.98 & $0.94-1.03$ \\
\hline Age at diagnosis & 1.03 & $1.02-1.04$ & 1.04 & $1.03-1.04$ & 1.04 & $1.03-1.04$ \\
\hline
\end{tabular}

Sex

\begin{tabular}{|c|c|c|c|c|c|c|}
\hline $\begin{array}{l}\text { Male } \\
\text { Female }\end{array}$ & $\begin{array}{l}1.00 \\
0.99\end{array}$ & $0.87-1.12$ & $\begin{array}{l}1.00 \\
0.86\end{array}$ & $0.77-0.97$ & $\begin{array}{l}1.00 \\
0.91\end{array}$ & $0.84-0.99$ \\
\hline \multicolumn{7}{|c|}{ Surgical treatment } \\
\hline $\begin{array}{l}\text { Resection } \\
\text { Palliative } \\
\text { No surgery } \\
\text { Unknown }\end{array}$ & $\begin{array}{c}1.00 \\
1.4 \\
3.14 \\
21.59\end{array}$ & $\begin{array}{c}1.07-1.83 \\
2.59-3.80 \\
17.03-27.36\end{array}$ & $\begin{array}{l}1.00 \\
3.81 \\
3.44 \\
3.43\end{array}$ & $\begin{array}{l}3.17-4.57 \\
2.95-4.00 \\
2.52-4.68\end{array}$ & $\begin{array}{l}1.00 \\
5.58 \\
3.53 \\
2.55\end{array}$ & $\begin{array}{l}4.90-6.35 \\
3.19-3.91 \\
2.00-3.26\end{array}$ \\
\hline \multicolumn{7}{|c|}{ Charlson co-morbidity score } \\
\hline $\begin{array}{l}0 \\
1 \\
2 \\
\geqslant 3 \\
\text { Unknown }\end{array}$ & $\begin{array}{c}1.00 \\
1.61 \\
1.59 \\
2.01 \\
\text { Omitted }\end{array}$ & $\begin{array}{l}1.35-1.93 \\
1.23-2.06 \\
1.54-2.65\end{array}$ & $\begin{array}{c}1.00 \\
1.22 \\
1.31 \\
1.84 \\
\text { Omitted }\end{array}$ & $\begin{array}{l}1.03-1.45 \\
1.02-1.68 \\
1.39-2.41\end{array}$ & $\begin{array}{c}1.00 \\
1.18 \\
1.66 \\
1.43 \\
\text { Omitted }\end{array}$ & $\begin{array}{l}1.03-1.35 \\
1.36-2.03 \\
1.10-1.85\end{array}$ \\
\hline
\end{tabular}

Index of Multiple Deprivation income category

\begin{tabular}{|c|c|c|c|c|c|c|}
\hline Most affluent & 1.00 & & 1.00 & & 1.00 & \\
\hline 2 & 1.12 & $0.91-1.38$ & 1.06 & $0.88-1.28$ & 0.94 & $0.83-1.07$ \\
\hline 3 & 1.16 & $0.94-1.42$ & 1.24 & $1.04-1.48$ & 1.01 & $0.88-1.14$ \\
\hline 4 & 1.25 & $1.02-1.54$ & 1.17 & $0.98-1.40$ & 1.05 & $0.92-1.20$ \\
\hline Most deprived & 1.31 & $1.07-1.62$ & 1.18 & $0.98-1.43$ & 1.14 & $1.00-1.31$ \\
\hline Unknown & 1.96 & $1.18-3.34$ & 1.48 & $0.90-2.44$ & 0.89 & $0.61-1.30$ \\
\hline
\end{tabular}

Dukes' stage at diagnosis

\begin{tabular}{|l|l|l|r|r|r|r}
\hline A & 1.00 & & 1.00 & 1.00 & $1.04-1.84$ & 1.67 \\
B & 1.97 & $1.22-3.17$ & 1.38 & $1.37-2.04$ \\
D & 1.86 & $1.17-2.98$ & 1.50 & $2.04-2.96$ \\
Unknown & 6.73 & $4.41-10.27$ & 3.76 & $2.90-4.88$ & 7.85 \\
\hline
\end{tabular}

Method of presentation

\begin{tabular}{|l|l|l|l|l|l|r|}
\hline Elective & 1.00 & & 1.00 & 1.00 & & \\
Emergency & 5.69 & $4.96-6.53$ & 2.31 & $1.04-2.64$ & $0.44-1.80$ \\
Unknown & 0.79 & $0.59-1.07$ & 0.88 & $0.55-1.43$ & $0.86-1.24$ \\
\hline
\end{tabular}

Abbreviations: $\mathrm{Cl}=$ confidence interval; $\mathrm{OR}=$ odds ratio.

${ }^{a}$ Mutually adjusted for all characteristics listed.

${ }^{\mathrm{b}}$ Omitted owing to collinearity with unknown surgical treatment.

reference to cancer. A more comprehensive linkage using all available HES data will in future enable the scale of this to be established.

The NCDR contains population-based data for all colorectal cancer patients diagnosed in England and this study includes over 90000 individuals. Using these routinely collected data, at no inconvenience to patients, we have identified some important areas which merit further research. For example, do delays in presentation, referral and diagnosis have a major role in early deaths or do they arise simply as a result of more aggressive disease? In addition, the reasons for the high proportion of missing data in those dying soon after diagnosis need to be established. It is not yet possible, however, to use the NCDR to fully answer these questions as it does not contain the depth of information required, such as details of primary care attendances or the dates that symptoms first presented. The NCIN continues to work to increase the scope of the NCDR, including linkage with general practitioner records of attendance, but alongside this, detailed prospective studies are required to provide a greater understanding of the premorbid health and health care attendance of patients who die early from colorectal cancer.

\section{ACKNOWLEDGEMENTS}

Amy Downing and Eva Morris were funded by the Cancer Research UK Bobby Moore Fund while undertaking this work 
(grant number C23434/A9805). This work was funded by a grant from the Hull York Medical School Research Strategy Committee.

\section{AUTHOR CONTRIBUTIONS}

UM, SO and EJAM designed the study. JDT linked the data. EJAM, $\mathrm{AD}$ and AA analysed the data. SO, PJF, PQ and JW helped with interpretation of the findings. EJAM and $\mathrm{AD}$ wrote the initial drafts of the manuscript. All authors contributed to the final version of the manuscript.

\section{CONFLICT OF INTEREST}

The authors declare no conflict of interest.

\section{REFERENCES}

Brewster DH, Clark DI, Stockton DL, Munro AJ, Steele RJC (2011) Early deaths after breast and colorectal cancer in Scotland. Brit J Cancer 104: 60-67.

Charlson ME, Pompei P, Ales KL, MacKenzie CR (1987) A new method of classifying prognostic comorbidity in longtitudinal studies: development and validation. J Chronic Dis 40: 373-383.

Elliss-Brookes L, McPhail S, Ives A, Greenslade M, Shelton J, Hiom S, Richards M (2012) Routes to diagnosis for cancer - determining the patient journey using multiple routine data sets. Brit J Cancer 107: $1220-1226$.

Engholm G, Kejs AMT, Brewster DH, Gaard M, Holmberg L, Hartley R, Iddenden R, Moller H, Sankila R, Thomson CS, Storm HH (2007)
Colorectal cancer survival in the Nordic countries and the United Kingdom: excess mortality risk analysis of five year relative period survival in the period 1999 to 2000. Int J Cancer 121: $1115-1122$.

Folkesson J, Engholm G, Ehrnrooth E, Kejs AM, Pahlman L, Harling H, Wibe A, Gaard M, Porvaldur J, Tryggvadottir L, Brewster DH, Hakulinen T, Storm HH (2009) Rectal cancer survival in the Nordic countries and Scotland. Int J Cancer 125: 2406-2412.

Moller H, Sandin F, Bray F, Klint A, Linklater K, Purushotham A, Robinson D, Holmberg L (2010) Breast cancer survival in England, Norway \& Sweden: a population-based comparison. Int J Cancer 127: $2630-2638$.

Moller H, Sandin F, Robinson D, Bray F, Klint A, Linklater K, Lambert PC, Pahlman L, Holmberg L, Morris EJ (2012) Colorectal cancer survival in socioeconomic groups in England: variation is mainly in the short-term after diagnosis. Eur J Cancer 48(1): 46-53.

Morris EJ, Sandin F, Lambert PC, Bray F, Klint A, Linklater K, Robinson D, Pahlman L, Holmberg L, Moller H (2011) A population-based comparison of the survival of patients with colorectal cancer in England, Norway and Sweden between 1996 and 2004. Gut 60(8): 1087-1093.

National Cancer Intelligence Network (2011) National Cancer Data Repository. http://www.ncin.org.uk/collecting_and_using_data/ national_cancer_data_repository/default.aspx Accessed December 2011.

NHS Connecting for Health (2009) OPCS Classification of Interventions and Procedures Version 4.5. The Stationery Office: London.

Office of the Deputy Prime Minister (2005) The English Indices of Deprivation 2004: Summary (revised). Office of the Deputy Prime Minister: London.

Verdecchia A, Francisci S, Brenner H, Gatta G, Micheli A, Mangone L, Kunkler I the EUROCARE-4 Working Group (2007) Recent cancer survival in Europe: a 2000-2002 period analysis of EUROCARE-4 data. Lancet Oncol 8: 784-796.

World Health Organisation (2004) ICD10 International Statistical Classification of Disease and Related Health Problems. World Health Organisation: Geneva.

Supplementary Information accompanies this paper on British Journal of Cancer website (http://www.nature.com/bjc) 